\title{
ESTABELECIMENTOS CHILDFREE: LIBERDADE DE INICIATIVA VS. DIREITOS DA CRIANÇA E DO ADOLESCENTE
}

\footnotetext{
${ }^{1}$ Bacharel em Direito pela Faculdade de Direito de Franca (FDF), mestra em Direito pela Universidade de Franca (Unifran) e doutora em Direito pela Faculdade Autônoma do Estado de São Paulo (FADISP). É docente assistente doutora vinculada ao Departamento de Direito Privado, Processo Civil e do Trabalho, lecionando nos cursos de graduação e pós-graduação stricto sensu em Direito da Universidade Estadual Paulista (UNESP), Faculdade de Ciências Humanas e Sociais, Franca. Currículo Lattes: http://lattes.cnpq.br/2799438446436625 . Contato: luciana.canavez@unesp.br

${ }^{2}$ Mestrando do programa de pós-graduação stricto sensu em Direito da Universidade Estadual Paulista (UNESP), Faculdade de Ciências Humanas e Sociais, Franca. É docente substituto bolsista vinculado ao Departamento de Direito Privado, Processo Civil e do Trabalho, lecionando as disciplinas de Direito do Consumidor, Direito Internacional Privado e Tutela dos Direitos Coletivos para o curso de graduação em Direito da mesma instituição. Currículo Lattes: http://lattes.cnpq.br/3172009565979544. Contato: pereiradeandrade.victorluiz@gmail.com

${ }^{3}$ Graduando em Direito pela Faculdade de Direito de Franca (FDF). É diretor encarregado da Pasta Solidariedade do Diretório Acadêmico "28 de março", vinculado à FDF; membro da Comissão da Jovem Advocacia, vinculada à OAB Franca; e estagiário da Procuradoria do Município de Franca, SP. Currículo Lattes: http://lattes.cnpq.br/4980469110634263. Contato: maylonclaudino13@ gmail.com
} 


\title{
RESUMO
}

Em decorrência do massivo desenvolvimento e constante aumento da dinamicidade da sociedade de consumo global contemporânea, ao mercado é imposto o acompanhamento de tendências e a atenção ao suprimento das necessidades e também demandas individuais de seus consumidores. Dentro deste contexto, surgem, impulsionados pelo ideário social precedente, os estabelecimentos childfree, empreendimentos comerciais que buscam o atendimento específico do nicho mercantil que se formou em torno da ideologia de mesmo nome. Contudo, por se tratar de uma ideologia excludente, discute-se os entraves jurídicos da atuação econômica no mercado e perante o ordenamento brasileiro. Com tal intuito, o presente artigo busca tratar, sem intenção de esgotar o tema, dos conflitos entre a liberdade de iniciativa privada e os direitos de crianças e a adolescentes, atentando também para os direitos do consumidor. $\mathrm{O}$ trabalho, guiando-se pelo método procedimental bibliográfico e método de abordagem dedutivo, baseia-se em obras de júris-filósofos, no acervo de leis brasileiro e também em resultados de pesquisas jurídicas e das demais áreas das ciências humanas e sociais aplicadas.

Palavras-chave: childfree. iniciativa privada. direitos da criança e do adolescente. direito do consumidor.

\begin{abstract}
As a result of the massive development and constant increase of the dynamism of the contemporary global consumer society, the market is required to monitor trends and give attention to supplying the needs and also the individual demands of its consumers. Within this context, the childfree establishments, commercial ventures that seek the specific service of the mercantile niche that has formed around the ideology of the same name, seem to appear, driven by its previous social ideology. However, because of its an excluding nature, there comes a need to discuss the legal implications of the battle between the freedom for economic activity the Brazilian legal order of protection. With this in mind, this article intends to deal with conflicts between the freedom of private initiative and the rights of children and adolescents, with no intention of exhausting the theme, but also with regard to consumer rights. The work, guided by the bibliographic procedure and deductive approach, is based on works by legal science authors, the Brazilian law and also on the results of researches performed in human and social sciences.
\end{abstract}

Keywords: Social Security, Public Policies, Fundamental Rights.

INTRODUÇÃO

Com o passar dos anos, com a profunda ampliação das modalidades de negócio, bem como o crescente sentimento individualista em nossa sociedade, aumentam-se as demandas por prestações de serviço segmentadas e voltadas a públicos específicos. Entretanto, em alguns casos, o oferecimento de tais prestações implica no estabelecimento de restrições ao acesso por parte dos demais consumidores.

É neste paradigma em que se inserem os estabelecimentos childfree, estabelecimentos coloquialmente considerados comuns que se recusam a prestar seus serviços e vender seus produtos a crianças e adolescentes, com vistas a satisfazer a demanda por ambientes frequentados apenas por adultos. 
Em se tratando de restrições a direitos, faz-se necessário analisar, sob a ótica do Direito brasileiro, quais os limites aplicáveis e quais as possíveis implicações que estabelecimentos de tal gênero oferecem frente aos direitos constitucionalmente consagrados.

Faz-se mister a análise das consequências e permeações para com os direitos da criança e do adolescente, bem como os direitos do consumidor e, por outro lado, quais as liberdades envolvidas, sobretudo conquanto às garantias à liberdade de iniciativa, de concorrência e de desempenho da atividade econômica em um sistema capitalista como o caso brasileiro.

Com a criação de estabelecimentos childfree, muitos veículos midiáticos e porta-vozes da sociedade se levantaram para discutir e, muitas vezes, protestar emocionalmente a existência de estabelecimentos comerciais que restrinjam a entrada de crianças e adolescentes, sem, na maior parte das vezes, considerar os direitos envolvidos e arguidos por ambos os lados.

Assim, o presente artigo possui como intuito apresentar a origem social de tais estabelecimentos, e assim discutir, dentro dos parâmetros legais atualmente vigentes no Brasil, qual a visão jurídica aplicável à criação e manutenção de tal nicho mercantil, buscando concluir a respeito de sua adequação para com os princípios e regras de nosso ordenamento, bem como discutir a possibilidade do estabelecimento de limites à aplicação de tais restrições ao público infanto-juvenil.

Mais especificamente, o trabalho discutirá a permeação de regras de proteção à criança e o adolescente frente ao exercício da liberdade de iniciativa e exploração da atividade econômica, trazendo também a possibilidade de consequências frente às garantias concedidas pelo Direito do Consumidor.

Para a construção desta pesquisa, foram utilizados os métodos dedutivo e bibliográfico, com uma discussão voltada à visão técnicadogmática do direito. $\mathrm{O}$ trabalho possui como base teórica fundamental as fontes jurídicas e formais de pesquisa, incluindo os acervos de leis e obras de júris-filósofos, doutrinadores e pesquisadores das áreas jurídicas e também áreas correlatas que permeiam o tema, tanto em esfera nacional quanto em esfera internacional. 
A partir dos anos 80, iniciou-se um movimento social denominado "childfree". A palavra vem do inglês, formada pela justaposição dos termos "criança" (child) e "livre" (free), e foi, inicialmente, utilizada para denominar a ideologia segundo a qual os indivíduos humanos, sobretudo mulheres, não são, nem devem ser, obrigados a gerar filhos próprios ou adotar.

Originalmente, a principal ideia por trás do movimento childfree, é a visão que busca conferir uma maior liberdade para indivíduos, no sentido de não considerar natural a obrigatoriedade de se ter filhos, situação que, para as mulheres, passou anos depois a ser denominada "maternidade compulsória".

A maternidade compulsória é a ideologia que possui como principal consequência a ideia de que uma mulher se tornaria "menos" ou "menos mulher" por não ter ou não querer ter filhos. É a ideia de que toda mulher possui um dever ou obrigação natural de procriar, e de que não se encontra dentro da normalidade, ou dos parâmetros de aceitabilidade sociais, que uma mulher opte por não gerar filhos.

Com o passar dos anos, o movimento ganhou maiores proporções, passando a integrar não somente a luta por um direito ao nãojulgamento por parte da sociedade em matéria de não-procriação, mas também um crescente sentimento de intolerância voltado a crianças e adolescentes.

Segundo psicólogos, este sentimento é gerado em decorrência do aumento do sentimento individualista em nossa sociedade contemporânea, um paradigma marcado pelo egoísmo e que encontraria, em crianças, focos de intolerância a comportamentos historicamente considerados naturais ${ }^{4}$.

Contudo, o crescente "sentimento childfree" acabou por gerar uma demanda econômica por espaços somente frequentados por adultos, espaços nos quais crianças e adolescentes, antes também frequentadores, deixaram de ser bem vindos ou mesmo tolerados.

\footnotetext{
${ }^{4}$ BRAND, Débora; OSTI, Marília. Psicólogas falam sobre o movimento childfree; confira. Curitiba: RICTV, set. 2017. 1 Vídeo, multimídia, son., duração 10:19 min. Disponível em: <https://www.youtube.com/watch?v=-9NcladjUa0>. Acesso em: 20 jun. 2018.
} 


\section{ESTABELECIMENTOS CHILDFREE: FUNDAMENTOS SUBJETIVOS VS. FUNDAMENTOS OBJETIVOS}

\section{Mas afinal, o que é um estabelecimento childfree?}

Um estabelecimento childfree é um estabelecimento comercial, visto socialmente enquanto "comum", que, por opção de seus donos e gestores, passa a impor restrições de entrada a consumidores crianças e adolescentes, membros de faixa etária inferior aos 18 anos completos, sendo admissível a presença de variações quanto às restrições conforme a idade, mesmo que acompanhados de seus pais ou responsáveis.

Dentre tais estabelecimentos incluem-se hotéis, restaurantes, clubes e outros que, tradicionalmente, não figuram dentre os espaços ditos "adultos", como se mostrariam as casas noturnas, danceterias, saunas ou outros estabelecimentos que recebem tal classificação etária por se tratarem, em consonância com o Estatuto da Criança e do Adolescente ${ }^{5}$ (ECA), enquanto nocivos para o desenvolvimento moral e mental do indivíduo. Desta forma, questiona-se, por diversas vias e argumentos, quais seriam as implicações jurídicas geradas pela atuação de tais empreendimentos no mercado de consumo.

Em uma primeira visão, ao encarar os aspectos subjetivos que permeiam ambas as partes da relação consumerista e antes de se considerar as reações emocionais de determinados setores da sociedade, algumas ponderações merecem relevância.

Do ponto de vista social, a partir dos olhos do público alvo do empreendedor, e por consequência, do próprio ponto de vista daquele que empreende, do indivíduo que busca satisfazer esta demanda, é de fácil constatação o forte sentimento de intolerância para com crianças e adolescentes. Neste contexto, podem ser utilizados argumentos comuns, trazendo referência a "gritos", "correria", "falta de modos" ou "falta de respeito" para justificar a restrição a tais públicos.

\footnotetext{
5 “Art. $3^{\circ} \mathrm{A}$ criança e o adolescente gozam de todos os direitos fundamentais inerentes à pessoa humana, sem prejuízo da proteção integral de que trata esta Lei, assegurando-se-lhes, por lei ou por outros meios, todas as oportunidades e facilidades, a fim de lhes facultar o desenvolvimento físico, mental, moral, espiritual e social, em condições de liberdade e de dignidade.”. BRASIL. Lei n. 8.069, de 13 de julho de 1990. Dispõe sobre o Estatuto da Criança e do Adolescente e dá outras providências. Diário Oficial da União, Brasília, DF: p. 13563, 16 jul. 1990a. Disponível em: <http://www.planalto.gov.br/ccivil_03/leis/18069.htm〉. Acesso em: 20 jun. 2018.
} 
Neste sentido, estudos apontam ${ }^{6}$ que, mesmo entre indivíduos que possuem intenções objetivamente concretas de gerar filhos, e mesmo que tais intenções se deem a curto prazo, pessoas sem filhos são mais propensas a possuir sentimentos negativos para com as crianças presentes à sua volta.

Contudo, partindo de uma visão alinhada ao princípio constitucional da proteção ao consumidor, a prática se mostra altamente discriminatória, por estar desrespeitando os direitos básicos do indivíduo ao negar-lhes a prestação do serviço ofertado. Caso a restrição fosse aplicada com base nos meros argumentos subjetivos do empresário, mesmo que derivados dos anseios de seu público alvo, sob argumentos como os expostos acima, estaríamos diante de clara situação de discriminação infundada, não passível de ser admitida pelas regras de nosso ordenamento jurídico.

Assim, baseando-se em tal fundamentação, consumidores crianças ou adolescentes, bem como os responsáveis que os acompanham, veriam-se amparados pelas regras de vedação à discriminação, visto que a mera rejeição individual e subjetiva ao público infantil ou infanto-juvenil não pode ser, em nenhuma instância, levada enquanto argumento legítimo para a restrição ao acesso do público aos espaços abertos.

Por outro lado, é preciso levar em conta a própria estruturação dos referidos empreendimentos para adequação à ideologia childfree. Donos de tais estabelecimentos não são obrigados a justificar a imposição de restrições com base em meras pontuações subjetivas ou mesmo em seus dissabores relativos a crianças e adolescentes.

Pelo contrário, uma empresa, ao restringir seu público utilizando a nomenclatura, classificação e regras childfree, pode optar por esclarecer seus clientes que a restrição se deve à aplicação de normas básicas de segurança e cuidado para com os indivíduos menores, não se baseando em argumentos subjetivos e superficiais como aqueles supramencionados.

\footnotetext{
${ }^{6}$ Um estudo realizado no Centro de Saúde da Universidade de Connecticut com 94 pacientes apontou que, em uma sala de espera de uma clínica de tratamento para infertilidade, pacientes sem filhos, mesmo com sérias intenções de os gerarem (por isso participando de tratamento para infertilidade) possuem forte tendência a desenvolver sentimentos negativos para com as crianças à sua volta, sendo aqueles que já os possuem mais pacientes e tolerantes. BUDINETZ, T. H. et al. Childless patients feel more negatively about pregnant providers and children in the office waiting room. Fertility and Sterility, Amsterdam, v. 100, n. 3, p. S410, set. 2013. Disponível em: <https://doi.org/10.1016/j.fertnstert.2013.07.620>. Acesso em: 20 jun. 2018.
} 
São apresentados, então, diversos fatores objetivos que visam justificar a aplicação de restrições ao acesso de crianças e adolescentes a tais estabelecimentos. Em um primeiro plano, não podem ser ignoradas as manifestas restrições materiais culturalmente e legislativamente consagradas.

Um empreendimento que oferece bebidas alcoólicas de maneira livre e irrestrita a seus consumidores, por exemplo, não é passível de ser frequentado por crianças ou adolescentes. Assim, é perfeitamente admissível que uma danceteria ou um bar restrinjam seu acesso a apenas o público adulto, uma vez que seus serviços ofertados apresentariam manifesta periculosidade física e psicológica aos indivíduos em formação.

O mesmo se aplica a locais de temática explicitamente sexual e adulta, como motéis, saunas e casas de banho, visto que oferecem reconhecido perigo à integridade moral de crianças e adolescentes.

Não se tratam apenas de vedações culturais. O Estatuto da Criança e do Adolescente, Lei $n^{\circ}$ 8.069/90, é claro ao expor, em seu artigo $149^{7}$, a competência para que a autoridade judiciária discipline através de portaria, ou dê autorização mediante alvará, a fim de decidir sobre a entrada e permanência desacompanhada ${ }^{8}$ de crianças e adolescentes em estádios, bailes, boates, estúdios e outros locais congêneres, elencados taxativamente ${ }^{9}$, conforme se expõe:

Art. 149. Compete à autoridade judiciária disciplinar, através de portaria, ou autorizar, mediante alvará:

I - a entrada e permanência de criança ou adolescente, desacompanhado dos pais ou responsável, em:

a) estádio, ginásio e campo desportivo;

b) bailes ou promoções dançantes;

c) boate ou congêneres;

\footnotetext{
${ }^{7}$ BRASIL. Lei n. 8.069, de 13 de julho de 1990. Dispõe sobre o Estatuto da Criança e do Adolescente e dá outras providências. Diário Oficial da União, Brasília, DF: p. 13563, 16 jul. 1990a. Disponível em: <http://www.planalto.gov.br/ccivil_03/leis/18069.htm>. Acesso em: 20 jun. 2018.

${ }^{8} \mathrm{~A}$ portaria judicial que proíba a entrada de crianças e adolescentes em determinado local se aplica somente àqueles que se encontrem desacompanhados de seus pais ou responsáveis. DIGIÁCOMO, Murillo José; DIGIÁCOMO, Ildeara Amorim. Estatuto da criança e do adolescente anotado e interpretado. Curitiba: Ministério Público do Estado do Paraná, Centro de Apoio Operacional das Promotorias da Criança e do Adolescente, 2010. p. 220.

${ }^{9}$ Sobre a prerrogativa dada ao Poder Judiciário para regulamentar sobre a entrada e permanência de crianças e adolescentes a determinados locais, é necessário ressaltar que a competência normativa da Justiça da Infância e da Juventude deverá respeitar as hipóteses do artigo 149 taxativamente. DIGIÁCOMO, Murillo José; DIGIÁCOMO, Ildeara Amorim. Estatuto da criança e do adolescente anotado e interpretado. Curitiba: Ministério Público do Estado do Paraná, Centro de Apoio Operacional das Promotorias da Criança e do Adolescente, 2010. p. 220.
} 
d) casa que explore comercialmente diversões eletrônicas;

e) estúdios cinematográficos, de teatro, rádio e televisão.

[...]

$\S 1^{\circ}$ Para os fins do disposto neste artigo, a autoridade judiciária levará em conta, dentre outros fatores:

a) os princípios desta Lei;

b) as peculiaridades locais;

c) a existência de instalações adequadas;

d) o tipo de freqüência habitual ao local;

e) a adequação do ambiente a eventual participação ou frequiência de crianças e adolescentes;

f) a natureza do espetáculo.

$\S 2^{\circ}$ As medidas adotadas na conformidade deste artigo deverão ser fundamentadas, caso a caso, vedadas as determinações de caráter geral (BRASIL, 1990a).

Ou seja, mesmo que aplicável apenas às situações elencadas em rol taxativo, a lei disciplina que a autoridade deverá levar em conta em seu julgamento: os princípios do ECA, as peculiaridades locais, a existência de instalações adequadas, o tipo de frequência habitual ao local e a adequação do ambiente à participação de crianças e adolescentes.

Desta forma, dado que, como já exposto, os locais denominados childfree não se tratam apenas de locais tradicionalmente restritos a crianças e adolescentes, mas sim de estabelecimentos ditos "comuns", tradicionalmente abertos a todos os públicos, como hotéis, restaurantes, lanchonetes, parques etc, é nestes estabelecimentos que, ao se demonstrar a postura childfree, questiona-se a legalidade para tal restrição, dado que, em uma visão cultural, não se encontram motivos para tal impedimento. Neste momento, então, os empreendimentos são chamados a oferecer justificativa razoável para a imposição de restrições.

Conquanto à restrição de crianças, os empreendimentos podem se valer de argumentos relacionados à segurança básica das mesmas, valendo-se de regras que visam assegurar a integridade física de tais indivíduos através da não permissão de acesso pelos mesmos. Desta forma, estariam se posicionando em consonância ao princípio protetivo do ECA, bem como se utilizando do argumento de que não se tratariam de instalações ou ambientes adequados à entrada e permanência dos mesmos.

Um restaurante, por exemplo, pode se dizer childfree com base no argumento de que não possui estrutura básica para a acomodação de crianças, como não possuir cadeiras especiais e talheres de tamanhos adequados ou mesmo através de seu cardápio. Ao servir apenas pratos de alta complexidade e, em determinados casos, que ofereçam grau de 
periculosidade $^{10}$ ao consumidor, crianças e adolescentes restariam inabilitados para consumo no local, visto que ambos carecem de capacidade para consentir para com tais hipóteses de risco.

Além disso, a própria arquitetura e decoração do local em questão podem se mostrar impróprias por possuir objetos pontiagudos em posições inadequadas ou mesmo em virtude de decorações fisicamente nocivas à integridade de tais consumidores. Como exemplo, é possível citar a hipótese de criação de um restaurante com temática medieval que opta por decorar suas paredes integralmente com réplicas de armas brancas utilizadas no período histórico. Haveria neste caso, sério risco a integridade física de crianças que, por seu comportamento natural, poderiam se machucar ao esbarrar contra algum de tais artefatos decorativos.

Neste exemplo, portanto, teríamos uma clara argumentação que daria base concreta à restrição de crianças. Contudo, resta o questionamento com relação a adolescentes. A ausência de estrutura adaptada não é razão adequada para restringir o acesso de adolescentes, visto que são indivíduos já não suscetíveis a normas de segurança tão rígidas quanto aquelas apresentadas às crianças.

Diferem-se, então, os níveis de restrição aplicáveis a crianças e adolescentes, distinguindo-se, portanto, os aspectos objetivos consideráveis para a oposição de restrições ao oferecimento de serviços a crianças e os argumentos aplicáveis a adolescentes.

Crianças são indivíduos em fase altamente sensível de seu desenvolvimento físico, portanto vulneráveis a uma quantidade incontável de situações de periculosidade física que impossibilitam sua permanência em determinados locais com base em regras relacionadas a sua segurança e integridade. Já no caso de adolescentes, estes encontram restrições não relativas às simples situações físicas, mas principalmente relacionadas aos aspectos temáticos e passíveis de gerar consequências psicológicas negativas em indivíduos em formação.

Desta forma, não seria admissível que se apresentasse a ausência de cadeiras ou talheres especiais como argumento para a restrição de adolescentes, mas sim que a presença de decoração com temática sexual adulta nas paredes do estabelecimento fosse apresentada enquanto fundamento para a restrição. É admissível, como exemplo, que um resort conceitual, com festas em locais abertos ou mesmo aquele que permita a

\footnotetext{
${ }^{10}$ Muitas vezes, bares e restaurantes com temática exótica oferecem alimentos e bebidas estrangeiros e que podem se mostrar nocivos ao consumidor em razão de características fisiológicas individuais.
} 
seus clientes o usufruto de determinadas liberdades individuais em espaços comuns, seja restrito para indivíduos menores de 18 anos.

É importante ressaltar que, em se tratando de local adulto, o aspecto objetivo que gera a restrição ao acesso por adolescentes é perfeitamente aplicável a crianças, visto que estas se encontram em grau ainda superior de vulnerabilidade. Assim, é visando a manutenção da integridade moral e psicológica de crianças e adolescentes que se restringe seu acesso a determinados espaços com base em fundamentos como aqueles supracitados.

Em suma, apenas crianças são passíveis de restrição com base em argumentos relacionados à manutenção de sua integridade física e conquanto à complexidade dos serviços prestados, enquanto ambos, crianças e adolescentes, são passíveis de restrição com base em argumentos relacionados à manutenção de sua integridade moral e psicológica, além da hipótese de oferecimento de serviços de alta periculosidade, situação em que adolescentes também se enquadrariam enquanto passíveis de restrição por motivos de integridade física, visto que são ainda incapazes de consentir à sua autocolocação em risco.

Diante do exposto, levanta-se o questionamento: se é vedada a restrição imotivada ou derivada de livre discriminação, até que ponto possui o empreendedor a prerrogativa de estruturar seu negócio de maneira intencionalmente imprópria a crianças e adolescentes, a fim de torná-lo inadequado a tais públicos e, consequentemente, estabelecer-se enquanto um empreendimento childfree?

\section{UM OLHAR TÉCNICO-DOGMÁTICO ACERCA DO FENÔMENO CHILDFREE EM ESTABELECIMENTOS COMERCIAIS}

Considerado o modelo de negócio childfree, a temática merece então ser observada conforme uma visão técnica e dogmática frente às normas jurídicas vigentes em nosso país. De maneira geral, para análise do tema serão necessárias ponderações em relação aos direitos da criança e do adolescente, os direitos do consumidor e, sobretudo, sobre normas relacionadas a liberdade de iniciativa, todos direitos garantidos sob a égide da Magna Carta brasileira de 1988. 
A Constituição Federal (CF) nos garante em seu artigo 227, caput, que é dever da família, da sociedade e do Estado garantir proteção especial ao jovem e à criança ${ }^{11}$. Conforme a redação constitucional, cabe às instituições supracitadas o dever de condicionar a convivência comunitária das crianças e dos adolescentes e protegê-los de qualquer tipo de situação discriminatória.

Logo, percebe-se que é essencial que a criança cresça e se desenvolva em sociedade. Entretanto, esse desenvolvimento em comunidade deve ser desempenhado de modo que não cause danos à criança ou adolescente. $\mathrm{O}$ artigo $220, \S 3^{\circ}$, inciso I da CF confere ao ente federal a competência para decidir sobre o local para apresentação de espetáculos, bem como o horário máximo para permanência de crianças e adolescentes, com finalidade explícita de protegê-los.

Art. 220. A manifestação do pensamento, a criação, a expressão e a informação, sob qualquer forma, processo ou veículo não sofrerão qualquer restrição, observado o disposto nesta Constituição. [...] $\S 3^{\circ}$ Compete à lei federal:

I - regular as diversões e espetáculos públicos, cabendo ao Poder Público informar sobre a natureza deles, as faixas etárias a que não se recomendem, locais e horários em que sua apresentação se mostre inadequada. $^{12}$

Essa preocupação é expressa ainda no artigo 227, que entrega ao Estado, família e sociedade o dever de proteger fisicamente e psicologicamente a criança e o adolescente de situações que os coloquem em risco.

Art. 227. É dever da família, da sociedade e do Estado assegurar à criança, ao adolescente e ao jovem, com absoluta prioridade, o direito à vida, à saúde, à alimentação, à educação, ao lazer, à profissionalização, à cultura, à dignidade, ao respeito, à liberdade e à convivência familiar e comunitária, além de colocá-los a salvo de

${ }^{11}$ BRASIL. Constituição (1988). Constituição da República Federativa do Brasil - 1988. Diário Oficial da União, Brasília, DF, n. 191-A, p. 1, 5 out. 1988. Disponível em: <http://www.planalto.gov.br/ccivil_03/constituicao/constituicaocompilado.htm>. Acesso em: 20 jun. 2018.

${ }^{12}$ BRASIL. Constituição (1988). Constituição da República Federativa do Brasil - 1988. Diário Oficial da União, Brasília, DF, n. 191-A, p. 1, 5 out. 1988. Disponível em: <http://www.planalto.gov.br/ccivil_03/constituicao/constituicaocompilado.htm>. Acesso em: 20 jun. 2018. 
toda forma de negligência, discriminação, exploração, violência, crueldade e opressão ${ }^{13}$.

O Estatuto da Criança e do Adolescente, em seu artigo 15, preceitua: "A criança e o adolescente têm direito à liberdade, ao respeito e à dignidade como pessoas humanas em processo de desenvolvimento e como sujeitos de direitos civis, humanos e sociais garantidos na Constituição e nas leis." ${ }^{14}$.

Portanto, crianças e adolescentes possuem o direito de estar em lugares que permitam o seu desenvolvimento. Assim, restrições à entrada de tais indivíduos em estabelecimentos que admitem acesso público não devem ser genericamente admitidas pelo ordenamento. O Estatuto da Criança e do Adolescente prevê no artigo 16, inciso I, a liberdade que os adolescentes e crianças têm de ir, vir e estar em locais públicos.

Contudo, deve-se questionar se o ambiente trará algum transtorno para o desenvolvimento dos mesmos, sendo que o bem-estar deve se sobrepor ao direito de ir e vir. Da mesma forma, embora o artigo 39, inciso IX, do Código de Defesa do Consumidor estabeleça que é vedado recusar a venda de bens ou prestação de serviço ${ }^{15}$, deve-se colocar a proteção das crianças e adolescentes de forma prioritária.

É justo e legal proteger crianças de ambientes que não foram preparados para recebê-las, visto que não podemos colocar o jovem em situação de risco. Por outro lado, também não se deve suportar ideologias discriminatórias baseadas em fundamentos puramente subjetivos, expressos por parcelas do movimento childfree. No âmbito da legalidade não é admissível que se profira discurso de ódio, a utilização de palavras pejorativas, ou mesmo que se refira aos indivíduos com palavras negativas simplesmente pelo fato de serem crianças ou adolescentes.

A referência degradante é o primeiro passo para tornar natural outros tipos de violência. Assim, a conduta se mostra objetivamente ilegal,

\footnotetext{
${ }^{13}$ BRASIL. Constituição (1988). Constituição da República Federativa do Brasil - 1988. Diário Oficial da União, Brasília, DF, n. 191-A, p. 1, 5 out. 1988. Disponível em: <http://www.planalto.gov.br/ccivil_03/constituicao/constituicaocompilado.htm>. Acesso em: 20 jun. 2018.

${ }^{14}$ BRASIL. Lei n. 8.069, de 13 de julho de 1990. Dispõe sobre o Estatuto da Criança e do Adolescente e dá outras providências. Diário Oficial da União, Brasília, DF: p. 13563, 16 jul. 1990a. Disponível em: <http://www.planalto.gov.br/ccivil_03/leis/18069.htm>. Acesso em: 20 jun. 2018.

${ }^{15}$ BRASIL. Lei n. 8.078, de 11 de setembro de 1990. Dispõe sobre a proteção do consumidor e dá outras providências. Diário Oficial da União, Brasília, DF: p. 1, 12 set. 1990b. Disponível em: <http://www.planalto.gov.br/ccivil_03/Leis/18078.htm>. Acesso em: 20 jun. 2018.
} 
pois atinge a dignidade da pessoa humana, ferindo o disposto no artigo $3^{\circ}$, inciso IV da Constituição Federal que revela como objetivo fundamental da República: “...Promover o bem de todos, sem preconceitos de origem, raça, sexo, cor, idade e quaisquer outras formas de discriminação" "16.

$\mathrm{O}$ artigo $5^{\circ}$ do ECA estabelece que "nenhuma criança ou adolescente será objeto de qualquer forma de discriminação"17. Não é natural, portanto, justificar a proibição da presença de tais indivíduos simplesmente porque choram, correm ou gritam, ou seja, por serem crianças, visto que tais comportamentos não fogem à naturalidade de sua condição de ser. Cabe ao Estado punir atitudes discriminatórias, conforme o art. $5^{\circ}$ da Constituição Federal, inciso XLI: “...A lei punirá qualquer discriminação dos direitos e liberdade fundamentais" $" 18$.

Infelizmente, crianças já não possuem espaços suficientes na sociedade, sendo poucos os municípios brasileiros que oferecem estruturas que possibilitem que jovens desenvolvam suas atividades de acordo com o intento legislativo. E se os espaços para as crianças e adolescentes são escassos é inaceitável a exclusão das mesmas de outros ambientes.

Todavia, como já exposto, não se pode de forma simplista afirmar que o movimento childfree é composto por pessoas que disseminam ódio às crianças e, portanto, não as toleram simplesmente pelo fato de serem crianças, visto que se trata de uma afirmação sem qualquer embasamento empírico.

Observa-se, então, que, diante do disposto no Estatuto da Criança e do Adolescente, só é plausível a proibição dos mesmos em determinados locais, desde que o indivíduo ali seja posto em risco. Essa deve ser a régua para verificar se é aceitável ou não a aplicação de tais restrições. Deve-se pesar o direito de segurança da criança e não a vontade subjetiva do empreendedor, sendo que a fundamentação que se busca é objetiva:

${ }^{16}$ BRASIL. Constituição (1988). Constituição da República Federativa do Brasil - 1988. Diário Oficial da União, Brasília, DF, n. 191-A, p. 1, 5 out. 1988. Disponível em: <http://www.planalto.gov.br/ccivil_03/constituicao/constituicaocompilado.htm>. Acesso em: 20 jun. 2018.

${ }^{17}$ BRASIL. Lei n. 8.069, de 13 de julho de 1990. Dispõe sobre o Estatuto da Criança e do Adolescente e dá outras providências. Diário Oficial da União, Brasília, DF: p. 13563, 16 jul. 1990a. Disponível em: <http://www.planalto.gov.br/ccivil_03/leis/18069.htm>. Acesso em: 20 jun. 2018.

${ }^{18}$ BRASIL. Constituição (1988). Constituição da República Federativa do Brasil - 1988. Diário Oficial da União, Brasília, DF, n. 191-A, p. 1, 5 out. 1988. Disponível em: <http://www.planalto.gov.br/ccivil_03/constituicao/constituicaocompilado.htm>. Acesso em: 20 jun. 2018. 
verificar se o ambiente é hostil para a interação social da criança ou adolescente.

Em uma visão substancialmente objetiva, o Código de Defesa do Consumidor apresenta outra vedação à prática abusiva que poderia, em determinado grau, ser interpretada em prol da obrigatoriedade de prestação de serviços a crianças e adolescentes.

Tal norma encontra-se exposta em seu art. 39, II e IX, conforme expõe:

Art. 39. É vedado ao fornecedor de produtos ou serviços, dentre outras práticas abusivas: [...]

II - recusar atendimento às demandas dos consumidores, na exata medida de suas disponibilidades de estoque, e, ainda, de conformidade com os usos e costumes;

$[\ldots]$

IX - recusar a venda de bens ou a prestação de serviços, diretamente a quem se disponha a adquiri-los mediante pronto pagamento, ressalvados os casos de intermediação regulados em leis especiais. 19

Contudo, sob a égide da Constituição da República Federativa do Brasil de 1988 (CRFB/88), consagrou-se o sistema econômico capitalista, regido sob o princípio da liberdade de iniciativa e com a prática de atividades econômicas regida conforme o sistema de economia de mercado e planejamento centralizado ${ }^{20}$.

Art. $1^{\circ}$ A República Federativa do Brasil, formada pela união indissolúvel dos Estados e Municípios e do Distrito Federal, constitui-se em Estado Democrático de Direito e tem como fundamentos:[...]

IV - os valores sociais do trabalho e da livre iniciativa [...]

Art. $170[\ldots]$

Parágrafo único. É assegurado a todos o livre exercício de qualquer atividade econômica, independentemente de autorização de órgãos públicos, salvo nos casos previstos em lei ${ }^{21}$.

\footnotetext{
${ }^{19}$ BRASIL. Lei n. 8.078, de 11 de setembro de 1990. Dispõe sobre a proteção do consumidor e dá outras providências. Diário Oficial da União, Brasília, DF: p. 1, 12 set. 1990b. Disponível em: <http://www.planalto.gov.br/ccivil_03/Leis/18078.htm>. Acesso em: 20 jun. 2018.

${ }^{20}$ FARIA, Werter R. Constituição econômica: liberdade de iniciativa e de concorrência. Porto Alegre: Sergio Antonio Fabris Editor, 1990. p. 57.

${ }^{21}$ BRASIL. Constituição (1988). Constituição da República Federativa do Brasil - 1988. Diário Oficial da União, Brasília, DF, n. 191-A, p. 1, 5 out. 1988. Disponível em: <http://www.planalto.gov.br/ccivil_03/constituicao/constituicaocompilado.htm>. Acesso em: 20 jun. 2018.
} 
O princípio da liberdade de comércio e indústria, de atuação econômica, de empresa ou de profissão, assegura aos particulares o direito de exercerem as atividades concernentes à produção e comercialização de bens e serviços, observadas as limitações impostas pelas leis e regulamentos." 22 .

Às vistas das liberdades econômicas, tornam-se ausentes a compulsão e a coerção, sem a interferência do Estado nas atividades dos cidadãos, que atuam dirigidos pelo próprio mercado e que têm, no Estado, a figura daquele que se propõe a evitar lesões ao funcionamento das relações econômicas ${ }^{23}$.

Assim, dado o status constitucional da liberdade de iniciativa econômica privada não enquanto direito fundamental, mas como base do Estado brasileiro, é de se considerar que, alcançados os requisitos legais ${ }^{24}$ e respeitadas as normas de ordem pública, a exploração da atividade privada não sofre quaisquer limitações e pode se moldar ao intento de seus empreendedores para suprir as necessidades demandadas por seu nicho consumidor.

Desta forma, o indivíduo empreendedor possui garantida sua liberdade de iniciativa para empreender da maneira que lhe for conveniente, desde que respeitadas as leis vigentes ${ }^{25}$. Neste ponto, é necessário ressaltar que não há, no Brasil, norma vigente que obrigue genericamente o fornecedor a adaptar sua prestação de serviços ao público jovem.

Com tal ausência normativa, pode-se inferir objetivamente que o Estado brasileiro admite a existência e criação de locais claramente impróprios para entrada e permanência de crianças e adolescentes.

\footnotetext{
${ }^{22}$ FARIA, Werter R. Constituição econômica: liberdade de iniciativa e de concorrência. Porto Alegre: Sergio Antonio Fabris Editor, 1990. p. 57.

${ }^{23}$ MISES, 1987 apud FARIA, Werter R. Constituição econômica: liberdade de iniciativa e de concorrência. Porto Alegre: Sergio Antonio Fabris Editor, 1990. p. 57.

${ }^{24}$ FARIA, Werter R. Constituição econômica: liberdade de iniciativa e de concorrência. Porto Alegre: Sergio Antonio Fabris Editor, 1990. p. 103.

25 “A economia regula-se por si própria, mas não de modo a haver uma atuação sem limites do setor privado naquela. Não há previsão alguma no ordenamento jurídico brasileiro de liberdade sem limites, tendo em vista que o próprio conceito de liberdade traz consigo o conceito de igualdade e, portanto, todos (sem qualquer forma de distinção) deveriam ser livres. E se houvesse a possibilidade de liberdade absoluta e total, alguns agentes não possuiriam algum tipo irrisório de liberdade." KAJINO, Lúcia Midori. Conflito principiológico no direito do trabalho: princípio de proteção ao trabalhador e o princípio da livre iniciativa privada. 2011. 198 p. Trabalho de conclusão (bacharelado - Direito). Universidade Estadual Paulista "Júlio de Mesquita Filho", Faculdade de Ciências Humanas e Sociais, Franca, 2011. p. 76.
} 
Trata-se, como exemplo, de situação diametralmente distinta das normas de proteção à pessoa com deficiência, consagradas através do Estatuto da Pessoa com Deficiência ${ }^{26}$, que pregam, de maneira geral (e acentuadamente em seus arts. 53 e seguintes) a obrigatoriedade da adaptação em prol da acessibilidade do indivíduo com deficiência, crianças e adolescentes não possuem tão genérica garantia legal.

\section{CONCLUSÃO}

Diante do exposto, é possível apontar que preferir restringir o direito de convívio social de um adolescente ou criança ao invés de buscar o tratamento humanitário, é deixar de entender que tais indivíduos são pessoas, seres humanos titulares de direitos e protegidos sob a égide constitucional. Desta forma, por se tratar de um entendimento puramente subjetivo, este não serve de base ou fundamentação suficiente para oferecer justificativa legal às atividades comerciais de empreendedores alinhados para com a ideologia e nicho comercial childfree.

Encontrando-se outra vertente de atuação, os empreendimentos childfree acabam se valendo de argumentação construída em prol da manutenção da integridade física e moral de crianças e adolescentes para se inserirem dentro da legalidade de nosso sistema jurídico. É através da argumentação baseada em fatores puramente objetivos, muitas vezes construídos intencionalmente para a finalidade específica de restringir tais públicos, que empreendimentos childfree acabam se eximindo de sua responsabilidade para com a discriminação subjetiva derivada do movimento que lhe conferiu demanda e razão de existência.

Sendo assim, a liberdade de iniciativa confere base legal para a estruturação de negócios que oferecem riscos à integridade de crianças e adolescentes, que, por sua vez, ao serem protegidos por regras constitucionais e presentes no Estatuto da Criança e do Adolescente, acabam excluídos de tais espaços de acesso antes público. Trata-se de uma prática que, apesar de derivada de uma demanda discriminatória, por adequar-se às regras do ordenamento jurídico em fatores objetivos, acabam

\footnotetext{
${ }^{26}$ BRASIL. Lei n. 13.146, de 6 de julho de 2015. Institui a lei brasileira de inclusão da pessoa com deficiência (Estatuto da Pessoa com Deficiência). Diário Oficial da União, Brasília, DF: p. 2, 7 jul. 2015. Disponível em: 〈http://www.planalto.gov.br/ccivil_03/_ato2015-2018/2015/lei/113146.htm>. Acesso em: 20 jun 2018.
} 
por impor restrições em seus negócios alinhadas às normas protetivas vigentes em nosso país, sendo, portanto, uma prática comercial passível de ser considerada legal.

\section{REFERÊNCIAS BIBLIOGRÁFICAS}

ANDERSON, Wyndi Marie; PLATI, Crystal. Contentedly childless: building a movement that embraces all choices. Conscience, v. 31, n. 1, p. 37, 2010. Disponível em:

<http://link.galegroup.com/apps/doc/A227279156/AONE?u=capes\&sid=AONE\&xid=c3e578b3>. Acesso em: 20 jun. 2018.

BLACKSTONE, Amy. Childless... or childfree?. Contexts, Berkeley, v. 13, n. 4, p. 68-70, nov. 2014. Disponível em: 〈https://doi-org.ez67.periodicos.capes.gov.br/10.1177/1536504214558221〉. Acesso em: 20 jun. 2018.

BRAND, Débora; OSTI, Marília. Psicólogas falam sobre o movimento childfree; confira. Curitiba: RICTV, set. 2017.1 Vídeo, multimídia, son., duração 10:19 min. Disponível em: $\langle$ https://www.youtube.com/watch?v=-9NcladjUa0>. Acesso em: 20 jun. 2018.

BRASIL. Lei n. 8.069, de 13 de julho de 1990. Dispõe sobre o Estatuto da Criança e do Adolescente e dá outras providências. Diário Oficial da União, Brasília, DF: p. 13563, 16 jul. 1990a. Disponível em: 〈http://www.planalto.gov.br/ccivil_03/leis/18069.htm>. Acesso em: 20 jun. 2018.

BRASIL. Lei n. 8.078, de 11 de setembro de 1990. Dispõe sobre a proteção do consumidor e dá outras providências. Diário Oficial da União, Brasília, DF: p. 1, 12 set. 1990b. Disponível em: <http://www.planalto.gov.br/ccivil_03/Leis/18078.htm>. Acesso em: 20 jun. 2018.

BRASIL. Lei n. 13.146, de 6 de julho de 2015. Institui a lei brasileira de inclusão da pessoa com deficiência (Estatuto da Pessoa com Deficiência). Diário Oficial da União, Brasília, DF: p. 2, 7 jul. 2015. Disponível em: 〈http://www.planalto.gov.br/ccivil_03/_ato2015-2018/2015/lei/113146.htm>. Acesso em: 20 jun 2018.

BUDINETZ, T. H. et al. Childless patients feel more negatively about pregnant providers and children in the office waiting room. Fertility and Sterility, Amsterdam, v. 100, n. 3, p. S410, set. 2013. Disponível em: 〈https://doi.org/10.1016/j.fertnstert.2013.07.620〉. Acesso em: 20 jun. 2018.

BULOS, Uadi Lammêgo. Constituição federal anotada. 8. ed. ver. e atual. até a Emenda Constitucional n.56/2007. São Paulo: Saraiva 2008.

DIGIÁCOMO, Murillo José; DIGIÁCOMO, Ildeara Amorim. Estatuto da criança e do adolescente anotado e interpretado. Curitiba: Ministério Público do Estado do Paraná, Centro de Apoio Operacional das Promotorias da Criança e do Adolescente, 2010.

FARIA, Werter R. Constituição econômica: liberdade de iniciativa e de concorrência. Porto Alegre: Sergio Antonio Fabris Editor, 1990. 
IDOETA, Paula Adamo. 'Não aceitamos crianças': avanço da onda 'childfree' é conveniência ou preconceito? BBC Brasil, São Paulo, 9 ago. 2017. Disponível em:

<https://www.bbc.com/portuguese/salasocial-40784489>. Acesso em: 20 jun. 2018.

KAJINO, Lúcia Midori. Conflito principiológico no direito do trabalho: princípio de proteção ao trabalhador e o princípio da livre iniciativa privada. 2011. 198 p. Trabalho de conclusão (bacharelado - Direito). Universidade Estadual Paulista "Júlio de Mesquita Filho", Faculdade de Ciências Humanas e Sociais, Franca, 2011.

NUCCI, Guilherme de Souza. Estatuto da criança e do adolescente comentado. São Paulo: Forense, 2015.

PARDELLAS, Sérgio. O marcusiano “childfree”. Istoé, São Paulo, 28 jul. 2017. Disponível em: $<$ https://istoe.com.br/o-marcusiano-childfree/>. Acesso em: 20 jun. 2018.

RICH, Stephanie et al. 'Unnatural', 'unwomanly', 'uncreditable' and 'undervalued': the significance of being a childless woman in Australian society. Gender Issues, New York, v. 28, n. 4, p. 226-247, dez. 2011. Disponível em: <https://link-springercom.ez67.periodicos.capes.gov.br/article/10.1007\%2Fs12147-011-9108-1>. Acesso em: 20 jun. 2018.

TANTURRI, Maria Letizia; MENCARINI, Letizia. Childless or childfree? Paths to voluntary childlessness in Italy. Population and Development Review, v. 34, n. 1, New York, p. 51-57, mar. 2008. Disponível em: 〈https://www-jstor-org.ez87.periodicos.capes.gov.br/stable/25434658>. Acesso em: 20 jun. 2018.

WAREN, Warren; PALS, Heili. Comparing characteristics of voluntary childless men and women. Journal of Population Research, New York, v. 30, n. 2, p. 151-170, 5 abr. 2013. Disponível em: <https://link-springer-com.ez67.periodicos.capes.gov.br/article/10.1007/s12546-012-9103-8>. Acesso em: 20 jun. 2018. 